\title{
Lacrimal Gland Fistula: Report of a Rare Case
}

\author{
${ }^{1}$ Hitendra P Singh, ${ }^{2}$ Sunil Kumar, ${ }^{3}$ Veerendra Verma, ${ }^{4}$ Nitika Gupta, ${ }^{5}$ Shahab A Usmani
}

\begin{abstract}
Congenital fistula of lacrimal gland is a rare condition. These are usually located just lateral to the lateral canthus of the eye. Authors encountered a case of lacrimal gland fistula that was present around $2 \mathrm{~cm}$ lateral to the lateral canthus of the right eye. The condition was appropriately managed with surgical excision, which resulted in successful outcome both cosmetically and functionally.
\end{abstract}

Keywords: Congenital lacrimal gland fistula, Lacrimal gland, Lacrimal gland fistula, Magnetic resonance imaging sinogram.

How to cite this article: Singh HP, Kumar S, Verma V, Gupta N, Usmani SA. Lacrimal Gland Fistula: Report of a Rare Case. Int J Otorhinolaryngol Clin 2017;9(2):58-60.

\section{Source of support: Nil}

Conflict of interest: None

\section{INTRODUCTION}

Lacrimal gland is located in the superior temporal orbital region. Fistula of lacrimal gland is an uncommon occurrence. It can be congenital, iatrogenic, and develop following trauma. Congenital fistula is an extremely rare condition. Such a case was first reported by Mackenzie. ${ }^{1}$ Putterman ${ }^{2}$ first described lacrimal gland fistula in a child. Furthermore, congenital misdirected lacrimal gland ductules were also described. ${ }^{3}$ Several authors reported formation of lacrimal gland fistula following upper eyelid surgery and following head trauma. ${ }^{4,5}$ So far, very few cases have been reported of congenital lacrimal gland fistula in world literature. Authors hereby intend to present a case of congenital unilateral lacrimal gland fistula, which was surgically excised at our center.

\section{CASE REPORT}

A 16-year-old male patient came to the ENT and Head and Neck Surgery Department, King George's Medical

\footnotetext{
${ }^{1,2}$ Associate Professor, ${ }^{3}$ Professor, ${ }^{4,5}$ Senior Resident

${ }^{1-5}$ Department of ENT and Head and Neck Surgery, King George's Medical University, Lucknow, Uttar Pradesh, India

Corresponding Author: Hitendra P Singh, Associate Professor Department of ENT and Head and Neck Surgery, King George's Medical University, Lucknow, Uttar Pradesh, India, Phone: +919456048923, e-mail: drhpsingh77@gmail.com
}

University, India, with complaints of watery discharge from an opening, which was present around $2 \mathrm{~cm}$ lateral to the lateral canthus. The parents reported that this opening was present since birth and watery discharge from the opening occurred every time the patient blinked. The patient had no history of trauma or any surgical intervention done for the same. On examination, Patient's visual acuity was normal along with normal ocular movements in both eyes. A small orifice could be seen in the skin, lateral to the external canthus of right eye at a distance of $18 \mathrm{~mm}$. The opening was round and less than $1 \mathrm{~mm}$ in diameter (Fig. 1). Clear, transparent fluid could be seen constantly discharging from the orifice. There was only slight excoriation of skin around the opening, but there was no evidence of inflammation. There was no tenderness or glandular enlargement around the opening. The lateral canthus was normally developed. The magnetic resonance imaging (MRI) sinogram was done and external opening was visualized in the skin overlying the frontoparietal suture line, along with the linear tract extending up to the right lacrimal gland (Fig. 2). There was no abnormality found in the orbit or periorbital soft tissue. Lacrimal gland was visualized normally. Diagnosis of lacrimal gland fistula was made and patient was advised surgical excision. For preoperative workup, routine hematological and biochemical investigations were ordered and obtained. The case was operated upon under general anesthesia. An ophthalmology colleague was called upon to render the help during dissection of fistula near the lacrimal gland. An elliptical skin incision enclosing the fistula was made.

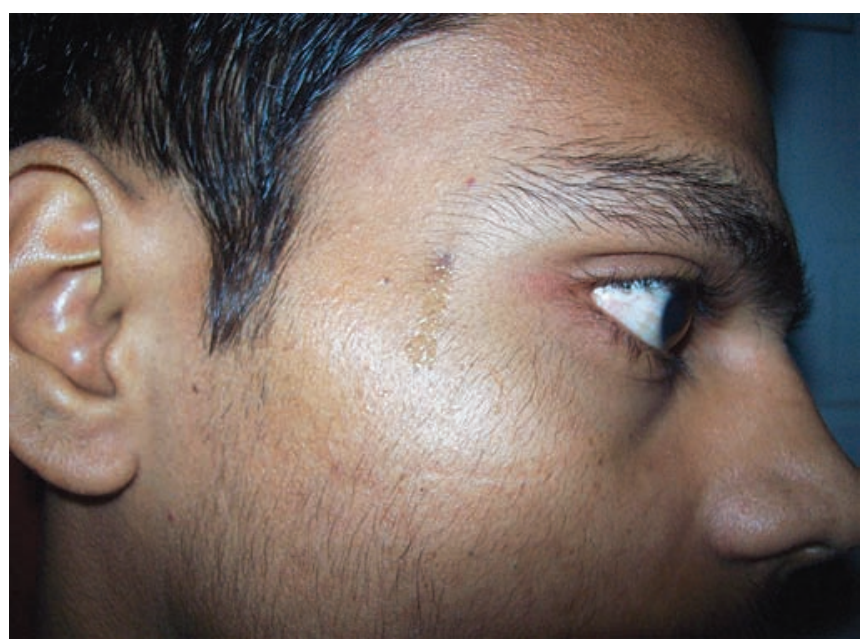

Fig. 1: A small fistulous opening lateral to the external canthus of the right eye 


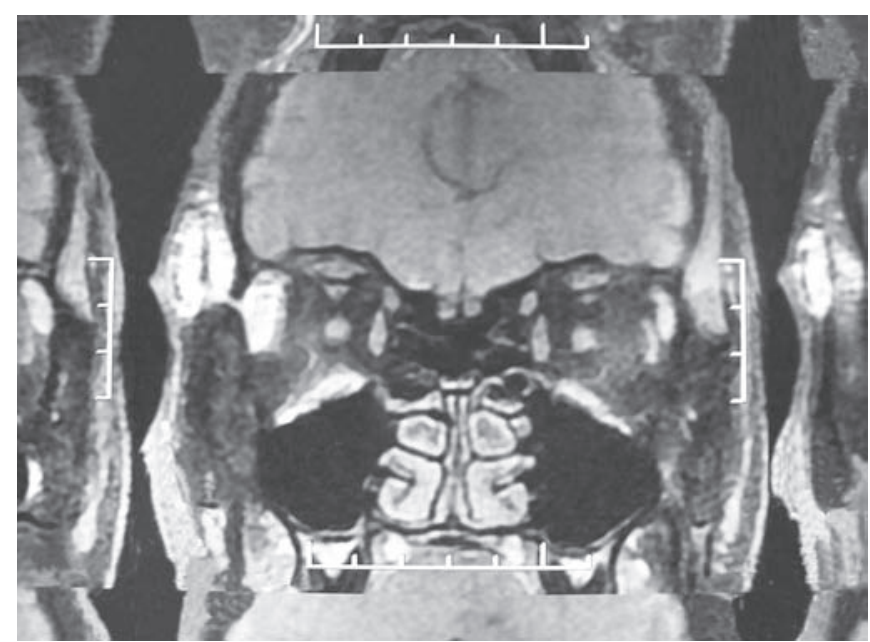

Fig. 2: The MRI sinogram showing linear tract starting from skin extending up to the right lacrimal gland overlying the frontotemporal suture line

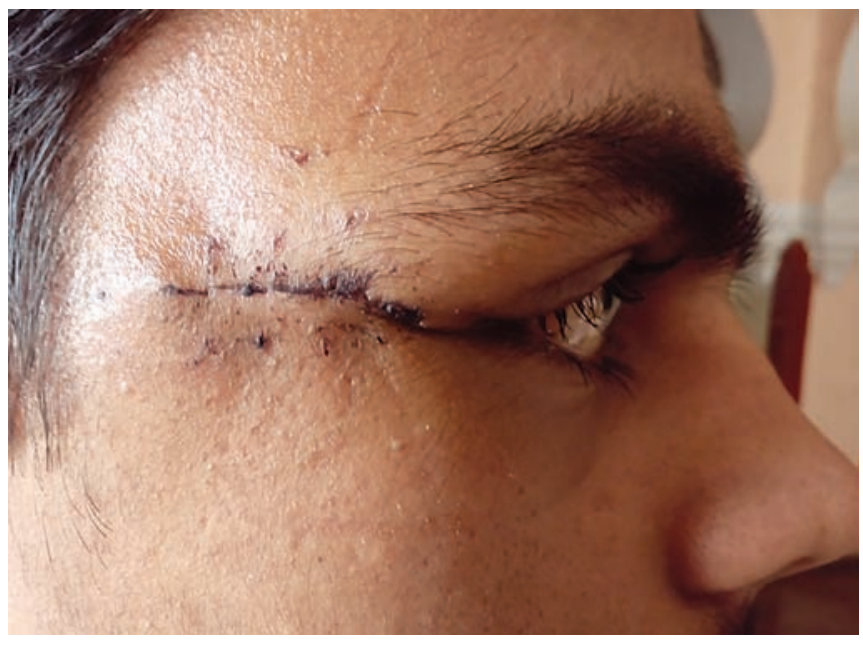

Fig. 4: Patient on postoperative day 5, note the swelling under the lid

After passing a probe, methylene blue dye was injected and the fistula was dissected out from the surrounding tissues all round; the track was followed until the lacrimal gland was reached (Fig. 3). The track was ligated by nonabsorbable suture and cut. Incision was closed in two layers. In immediate postoperative period, the patient had swelling over lid, which subsided within 4 days (Fig. 4). After 2 weeks, the incision line was healthy. There was no swelling over the lid and surrounding area. There was unobstructed flow of tear in the conjunctival sac (Fig. 5). There was no cosmetic deformity. At 6 months follow-up, patient was satisfied and asymptomatic.

\section{DISCUSSION}

Congenital lacrimal apparatus anomalies are rare and lacrimal gland fistula is a rarer occurrence. Different authors have reported different sites of congenital fistula of lacrimal gland like presentation of fistula in the midline of the upper lid just above tarsal plate ${ }^{6}$ and

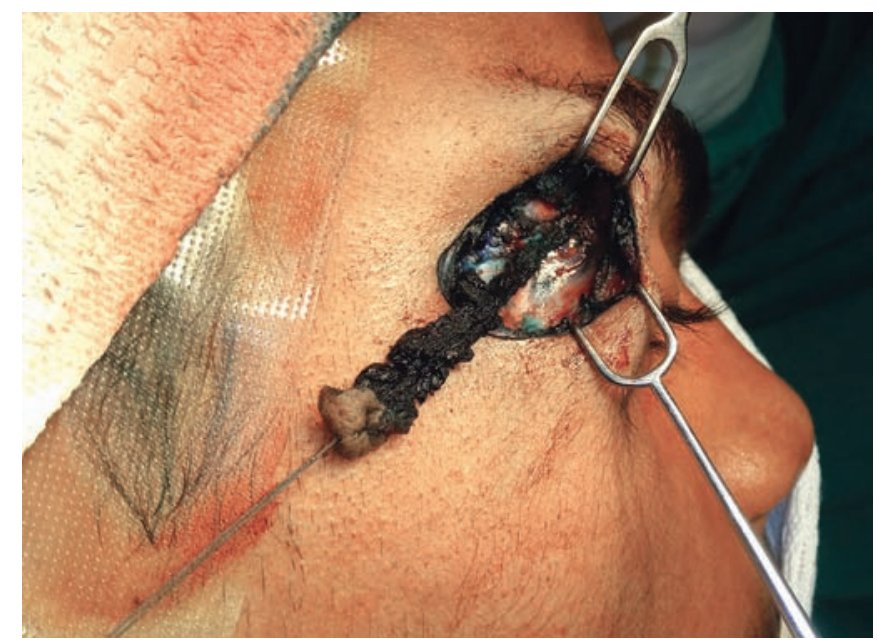

Fig. 3: Intraoperative photograph showing complete fistulous tract (bluish discoloration is due to methylene blue dye)

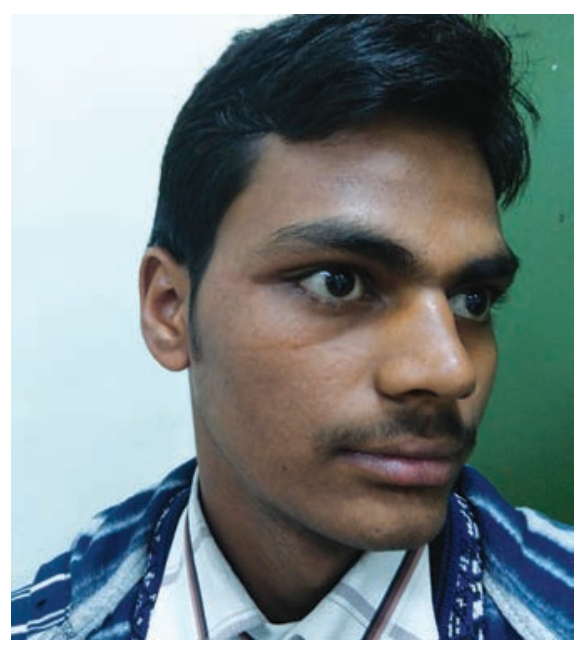

Fig. 5: Patient at 2 weeks of follow-up

lateral to the midline. ${ }^{7}$ Most authors reported the fistula at the same site as in our case. ${ }^{8-12}$

Patients with congenital fistula of the lacrimal gland commonly present with epiphora ${ }^{2,7-11}$ or with a purulent discharge from a fistula, which has undergone cystic dilatation with secondary infection..$^{13}$ It is interesting to note that despite the congenital nature of these fistulae, the clinical presentation is often delayed for many years after birth, as described in a case report, in which bilateral fistulae had remained asymptomatic for 35 years. ${ }^{13}$ This is probably due to the effect of evaporation on the discharge, which is often small in amount and intermittent in nature. Some authors reported presence of small hair around the orifice to be the characteristic sign of the condition being congenital. ${ }^{6,12,14} \mathrm{In}$ our patient, the opening was present in the skin temporal to lateral canthus, and there were hair as normally present in that region, but not specifically around the orifice. The lacrimal gland fistula was also found to be associated with other congenital anomalies ${ }^{8}$; however, there was no other congenital anomaly present in our patient. 
Surgical excision of fistula along with the adjoining portion of lacrimal gland is done by most, ${ }^{8,13}$ but in a study, the duct was transplanted rather than excised and they reported that transplantation prevents hydrops of the gland. ${ }^{12}$ In our case, we did not remove the part of the gland to avoid decrease in lacrimation and subsequent difficulties to the patient. The patient was followed up and had no functional or cosmetic problem.

\section{REFERENCES}

1. Mackenzie, W. System of ophthalmology. Vol. III. Part 2. London: Henry Kimpton; 1830. p. 921.

2. Putterman M. Eyelid epiphora secondary to lacrimal gland fistula. Ophthalmic Surg 1980 Oct;11(10):682-685.

3. Cogen MS, Lewis AR, Kelly AG. Anomalous lacrimal ductule: case report and review. J Pediatr Ophthalmol Strabismus 1994 Sep;31(5):327-329.

4. Ahn YJ, Jung SK, Paik JS, Yang SW. Lacrimal gland fistula after cosmetic lateral canthoplasty. J Craniofac Surg 2013 Jul;24(4):1317-1318.
5. Demir C, Toprak I, Gungen S, Arslan A. Lacrimal gland fistula following severe head trauma. Case Rep Med 2015 Feb;2015:534985.

6. Schornstein, T. System of ophthalmology. Vol. III. Part 2. London: Henry Kimpton; 1935. p. 921.

7. Terlinck, H. System of ophthalmology. Vol. III. Part 2. London: Henry Kimpton; 1910. p. 921.

8. Ling WP. Anomalous duct of lacrimal gland associated with other congenital anomalies. Am J Ophthalmol 1926 Jan;9(1):1-2.

9. Damato FJ. Congenital fistula of the lacrimal gland. $\mathrm{Br}$ J Ophthalmol 1956 Aug;40(8):506-508.

10. Bergdolt K, Heimke U. Congenital fistula of the lacrimal gland. Klin Monbl Augenheilkd 1980 Jun;176(6):972-974.

11. Malhotra M. Congenital fistula of the lacrimal duct. Br J Ophthalmol 1956 May;40:559-561.

12. Sinha A, Rahman A. Aberrant fistula of the lacrimal gland. Indian J Ophthalmol 1983 Mar;31(2):75-76.

13. Blanksma L, van de Pol BA. Congenital fistulae of the lacrimal gland. Br J Ophthalmol 1980 Jul;64(7):515-517.

14. Duke Elder, S. System of ophthalmology. Vol. III. Part 2. London: Henry Kimpton; 1964. p. 921. 